\title{
Erratum to: Influence of health information levels on postpartum depression
}

\author{
Sabrina Youash • M. Karen Campbell • William Avison • \\ Debbie Penava • Verinder Sharma • Bin Xie
}

Published online: 1 October 2013

(C) Springer-Verlag Wien 2013

\section{Erratum to: Arch Womens Ment Health}

\section{DOI 10.1007/s00737-013-0368-5}

The original version of this article unfortunately contained spelling errors. The names of "M. Karen Campbell" and "Debbie Penava" are now corrected in the author group of this article.

The online version of the original article can be found at http://dx.doi.org/ 10.1007/s00737-013-0368-5.

S. Youash $(\varangle) \cdot$ M. K. Campbell $\cdot$ W. Avison $\cdot$ B. Xie

Department of Epidemiology and Biostatistics,

University of Western Ontario, Kresge Building Room K201,

London, Ontario N6A 5C1, Canada

e-mail: syouash@gmail.com

W. Avison

Department of Sociology, University of Western Ontario, London, Ontario, Canada

D. Penava

Department of Obstetrics and Gynecology,

University of Western Ontario, London, Ontario, Canada

V. Sharma $\cdot$ B. Xie

Department of Psychiatry, University of Western Ontario,

London, Ontario, Canada 